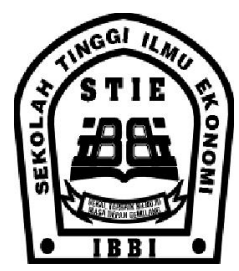

ISSN 1858-3199

JURNAL

MANAJEMEN BISNIS

STIE IBBI

\title{
DIVIDEND PAYOUT RATIO, INSIDER OWNERSHIP, LEVERAGE, PROFITABILITAS, FIRM SIZE DAN NILAI PERUSAHAAN
}

\author{
Hasrul Siregar \\ Sekolah Tinggi Ilmu Ekonomi IBBI \\ email : hasrul_siregar@yahoo.co.id
}

\begin{abstract}
Penelitian ini bertujuan untukmenganalisispengaruhinsider ownership, leverage, profitabilitas, firm sizedandividend payout ratioterhadapnilaiperusahaan. Model analisis ynang digunakan adalah regressi linier berganda. Sampel dalam penelitian adalah 10 perusahaan real estate yang terdaftar di Bursa Efek Indonesia periode 2010-2012. Hasil penelitian menunjukkan bahwa insider ownership, leverage, profitabilitas, firm sizedandividend payout ratiomempunyaipengaruh secara simultanterhadap nilai perusahaan ( price book value ). Namun secara partial insider ownershipdandividend payout ratiotidak berpengaruhterhadap nilai perusahaan.
\end{abstract}

Keywords: insider ownership, nilai perusahaan. 


ISSN 1858-3199
JURNAL
MANAJEMEN BISNIS
STIE IBBI

\section{PENDAHULUAN}

Pada prinsipnya perusahaan didirikan dalam rangka meningkatkan kemakmuran pemegang saham. Hal ini dapat diwujudkan dengan meningkatnya harga saham. Kenaikan harga saham tersebut merupakan gambaran meningkatnya nilai perusahaan. Untuk mencapai hal tersebut, pemilik perusahaan akan menggunakan agency dalam hal ini disebut manajer perusahaan. Sering terjadi bahwa manajer dalam mengelola perusahaan bertindak oportunis untuk mencapai keuntungan pribadi. Adakalanya keputusan agency tidak sesuai dengan keinginan pemilik. Misalnya apakah perusahaan membagi laba dalam bentuk dividend atau investasi dalam laba ditahan untuk peningkatan investasi masa depan.

Keputusan yang lain yang sering bertentangan adalah keputusan penggunaan hutang sebagai sumber pendanaan. Pemilik adakalanya lebih menyenangi menggunakan hutang untuk membiayai investasi daripada menggunakan ekuitas. Pemilik menganggap dengan menggunakan hutang berarti free cash flow lebih akan menjadi lebih kecil karena adanya cicilan hutang dan bunga. Pemilik menganggap bahwa ini merupakan sebagai bentuk pengawasan kepada manajer, dalam arti kebebasan untuk menggunakan kas menjadi lebih kecil. Sementara itu, manajer menganggap penggunaan hutang akan menempatkan posisi perusahaan kepada tingkat yang lebih beresiko karena porsi hutang yang lebih besar dibanding ekuiti.

Bentuk pengawasan lainnya yang efektif adalah mengikut sertakan insider ( manajer ) menjadi pemegang saham, sering disebut dengan insider ownership . Dengan keikutsertaan manajer sebagai pemilik maka manajer akan lebih berhati-hati dalam pengambilan keputusan. Hal ini berarti dapat meningkatkan nilai perusahaan.

Peningkatan nilai perusahaan tentu sangat dipengaruhi oleh laba yang dicapai ( ROA), argumen dasar semakin tinggi laba semakin tinggi nilai perusahaan. Ukuran perusahaan ( firm size ) juga sangat menentukan nilai perusahaan. Semakin besar ukuran perusahaan semakin besar asset yang digunakan untuk meningkatkan keuntungan dan akan meningkatkan nilai perusahaan. Pembagian dividend juga erat kaitannya dengan perusahaan. Secara logika besarnya dividen akan sangat tergantung dengan laba yang dicapai, juga ditentukan oleh kebijakan manajer apakah membagi laba dalam bentuk dividend atau tidak dibagikan. Banyak pandangan yang berbeda tentang masalah ini, ada yang berpendapat semakin tinggi dividend semakin tinggi nilai perusahaan karena semakin tinggi kepercayaan investor. Sebagian lain berpendapat dividend justru dapat menurunkan nilai perusahaan, karena dapat menurunkan besarnya tambahan modal untuk investasi mendatang. Keputusan dividend adalah merupakan keputusan yang sering diperdebatkan.

Beberapa penelitian sejenis seperti Hardiningsih (2011) menyatakan bahwa insider ownership, firm size, pertumbuhan perusahaan, kinerjaterbuktimempengaruhinilaiperusahaan.

Sementara itu kepemilikan institusional, dividend, hutang tidak berpengaruh terhadap nilai perusahaan. Selanjutnyahasilpenelitian Lestari et.all.(2013) menyatakankebijakandividentidakberpengaruhsignifi kanterhadapnilaiperusahaan.Hasilinisejalandengante ori yang dikemukakanolehModligianidan Miller (1996)

yang berpendapatbahwakebijakandividenadalahtidakrelev an yang berartibahwatidakadakebijakandividen yang optimal,

karenakebijakandividentidakmempengaruhinilaiperu sahaan.Hasilpenelitianinijugadidukungolehpenelitian yang dilakukanolehSofyaningsihdanHardiningsih (2011) yang menyatakanbahwakebijakandividentidakberpengaru hterhadapnilaiperusahaan.

\section{KAJIAN LITERATUR}

Insider Ownershipdan NilaiPerusahaan

Menurutagency teory, pemisahanantarakepemilikandanpengelolaanperusah aandapatmenimbulkankonflikkeagenan.Konflikkeag enandisebabkanprinsipaldanagenmempunyaikepenti ngansendiri-sendiri

yang 
ISSN 1858-3199

JURNAL

MANAJEMEN BISNIS

STIE IBBI

salingbertentangankarenaagendan principal berusahamemaksimalkanutilitasnyamasing-masing.

MenurutHaruman

(2008),

perbedaankepentinganantaramanajemendanpemegan gsahammengakibatkanmanajemenberperilakucurang dantidaketissehinggamerugikanpemegangsaham.

Olehkarenaitudiperlukansuatumekanismepengendali an

yang

dapatmensejajarkanperbedaankepentinganantaraman ajemendenganpemegangsaham.Manajer yang sekaliguspemegangsahamakanmeningkatkannilaiper usahaankarenadenganmeningkatkannilaiperusahaan, makanilaikekayaannyasebagaipemegangsahamakan meningkatjuga.

Penelitian

yang

mengkaitkankepemilikanmanajemen(insider

ownership)

dengannilaiperusahaantelahbanyakdilakukannamund enganhasil yang berbeda-beda pula.PenelitianSolihadanTaswanmenemukanhubung an yang signifikandanpositifantarakepemilikanmanajemen(in sider ownership) dannilaiperusahaan.

Leverage danNilai Per usahaan

Sebuahperusahaandikatakantidaksolvabelapabila

total hutangperusahaanlebihbesardaripada total asset yang dimilikiperusahaan. Dengansemakintingginyarasioleverage

menunjukkansemakinbesarnyadana yang disediakanolehkreditur. Hal tersebutakanmembuat investor berhati-hatiuntukberinvestasi di perusahaan yang rasioleverage nyatinggikarenasemakintinggirasioleveragenyasema kintinggi pula resikoinvestasinya (Weston dan Copeland, 2007).

Profitabilitas danNilai Perusahaan

Profitabilitasadalahtingkatkeuntunganbersih yang mampudiraiholehperusahaanpadasaatmenjalankanop erasinya.Keuntungan yang layakdibagikankepadapemegangsahamadalahkeuntu ngan yang diperolehsemakinbesarkemampuanperusahaanuntuk membayarkandividennya.
Profit yang tinggiakanmemberikanindikasiprospekperusahaan yang baiksehinggadapatmemicu investor untukikutmeningkatkanpermintaansaham.

Selanjutnyapermintaansaham yang meningkatakanmenyebabkannilaiperusahaanjugame ningkat. Hal tersebutmengindikasikanbahwa investor mempertimbangkanvariabeltingkatprofitabilitasseba gaisalahsaturasionalisasimerekadalampengambilank eputusaninvestasi.Fenomenatersebutmenunjukanbah watingkatprofitabilitasmerupakaninsentifbagipening katannilaiperusahaan.

Firm SizedanNilai Perusahaan

Ukuranperusahaandalampenelitianinimerupakancer minanbesarkecilnyaperusahaan yang nampakdalamnilai total aktivaperusahaan. Dengansemakinbesarukuranperusahaan, makaadakecenderunganlebihbanyak investor yang menaruhperhatianpadaperusahaantersebut.Hal

inidisebabkankarenaperusahaan yang besarcenderungmemilikikondisi yang lebihstabil.Kestabilantersebutmenarik investor untukmemilikisahamperusahaantersebut.Kondisiters ebutmenjadipenyebabatasnaiknyahargasahamperusa haan di pasar modal.Investor memilikiekspektasi yang besarterhadapperusahaanbesar.Ekspektasiinsvestorb erupaperolehandividendariperusahaantersebut.Penin gkatanpermintaansahamperusahaanakandapatmemac upadapeningkatanhargasaham di pasar modal. Peningkatantersebutmenunjukkanbahwaperusahaand ianggapmemiliki "nilai" yang lebihbesar.

\section{Dividen Payout Ratio dan Nilai Per usahaan}

Modigliani Miller dalam Brigham (2010)berpendapatbahwadividentidakrelevan yang berartitidakadakebijakan yang optimal karenadividentidakmempengaruhinilaiperusahaan. Gordon-

Lintnerberpendapatdividenlebihkecilresikonyadaripa dacapital gain, sehinggadividensetelahpajakdanmenawarkandividen yield yang lebihtinggiakanmeminimumkanbiaya modal. Sedangkankelompok lain 


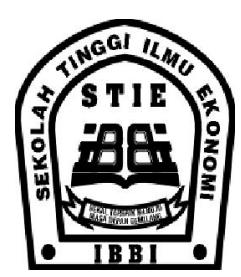

berpendapatbahwakarenadividencenderungdikenaka npajakdaripadacapital gain, maka investor akanmemintatingkatkeuntungan yang lebihtinggiuntuksahamdengandividend yield. Denganadanyadividen payout ratio (DPR) yang lebihrendahakanmemaksimumkannilaiperusahaan.

Dari ketigapendapat yang nampakbertentangantersebut, jikamempertimbangkankandunganinformasi, makadapatdikatakanbahwapembayarandividendilihat sebagaisignalbahwaperusahaanmemilikiprospek yang baik.Sebaliknyapenurunanpembayarandividenakandi liatsebagaiprospekperusahaan yang buruk. Makadalamhalinikebijakandividenberpengaruhpositi fterhadapnilaiperusahaan.

\section{METODE PENELITIAN}

Model analisis yang digunakan dalam penelitian ini adalah analisis regressi linier berganda. Sampel terdiri dari 10 perusahaan real estate yang terdaftar di BEI. Periode waktu penelitian adalah tahun 2010, 2011 dan 2012. Data diperoleh dari sumber eksternal ICMD yang dikeluarkan oleh Bursa Efek Indonesia. Dari data yang diperoleh dilakukan beberapa uji antara lain uji normalitas, uji multikolinieritas, uji autokorelasi dan uji heterokedastisitas. Untuk mengetahui pengaruh variabel bebas terhadap variabel terikatnya dilakukan uji $\mathrm{F}$ dan uji t.

\section{Defenisi Operasional Variabel}

Variabel-variabel yang digunakan dalam penelitian ini sebagai berikut :

\section{Insider ownership (X1):}

Merupakanpemegangsahamdaripihakmanajemen yangsecaraaktifikutdalam pengambilankeputusanperusahaan. Dapat diukur dengan $=$ JUMLAH SAHAM YANG DIMILIKI INSIDER / TOTAL SAHAM BEREDAR

\section{Leverage ( $X 2$ )}

Merupakanpengukurbesarnyaaktiva yang dibiayaidenganhutang-hutangyang digunakanuntukmembiayaiaktivaberasaldarikreditur,
ISSN 1858-3199

JURNAL

MANAJEMEN BISNIS

STIE IBBI

bukandaripemegangsahamataupundariinvestor.

Rasio yang digunakan = TOTAL HUTANG / TOTAL AKTIVA

\section{Profitabilitas( X3)}

Merupakanperusahaanuntuk

menghasilkanlabapadamasamendatang

danmerupakanindikatordari

keberhasilanoperasiperusahaan. Rasio yang digunakan ROA = LABA / TOTAL AKTIVA

\section{Firm Size( X4)}

Merupakancerminanbesarkecilnyaperusahaanyang dapat diukur dari total aktiva perusahaan. Dalam penelitian ini diukur dari Firm Size $=$ Ln TOTAL ASSET

\section{DividenPayoutRatio( X5)}

Merupakanbagiandarilababersih yangdibagikankepadapemegangsahamatauakanditah andalambentuklabaditahan. DPR = DIVIDEND PER SHARE / EARNING PER SHARE

\section{NilaiPerusahaan ( Y )}

Merupakanpersepsiinvestorterhadaptingkatkeberhasi lanperusahaanyangseringdikaitkandenganhargasaha $\mathrm{m}$. Diukur dengan PBV = HARGA SAHAM PER LEMBAR / NILAI BUKU PER LEMBAR SAHAM.

\section{HASIL DAN PEMBAHASAN}

Tabel 1. Hasil Uji Asumsi Klasik

\begin{tabular}{|l|l|l|l|l|l|}
\hline \multicolumn{2}{|c|}{ NILAI } & KPK & \multicolumn{2}{l|}{ KESIMPULAN } \\
\hline $\begin{array}{l}\text { Asym. } \\
\text { Sig ( 2 } \\
\text { tailed ) }\end{array}$ & 0,349 & & $\begin{array}{l}> \\
0,05\end{array}$ & \multicolumn{2}{l|}{ NORMAL } \\
\hline & VIF & Glesjer & \multicolumn{2}{|c|}{ VIF <10, Glesjer > 5\% } \\
\hline IO & 1,489 & 0,728 & $\begin{array}{l}\text { TDK } \\
\text { MULTI }\end{array}$ & $\begin{array}{l}\text { TDK } \\
\text { HETERO }\end{array}$ \\
\hline
\end{tabular}




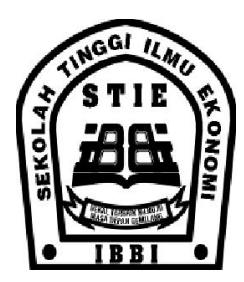

\begin{tabular}{|l|l|l|l|l|}
\hline LEV & 1,007 & 0,217 & $\begin{array}{l}\text { TDK } \\
\text { MULTI }\end{array}$ & $\begin{array}{l}\text { TDK } \\
\text { HETERO }\end{array}$ \\
\hline ROA & 1,542 & 0,726 & $\begin{array}{l}\text { TDK } \\
\text { MULTI }\end{array}$ & $\begin{array}{l}\text { TDK } \\
\text { HETERO }\end{array}$ \\
\hline FS & 1,478 & 0,950 & $\begin{array}{l}\text { TDK } \\
\text { MULTI }\end{array}$ & $\begin{array}{l}\text { TDK } \\
\text { HETERO }\end{array}$ \\
\hline DPR & 1,478 & 0,409 & $\begin{array}{l}\text { TDK } \\
\text { MULTI }\end{array}$ & $\begin{array}{l}\text { TDK } \\
\text { HETERO }\end{array}$ \\
\hline $\begin{array}{l}\text { Durbin } \\
\text { Watson }\end{array}$ & 1,845 & & $\begin{array}{l}\text { TDK } \\
\text { AUTOKOLERASi }\end{array}$ \\
\hline
\end{tabular}

Sumber : Pengolahan Data ( 2014 )

Dapat dilihat bahwa hasil uji asumsi klasik menunjukkan bahwa data terdistribusi secara normal, tidak terjadi gejala autokoresi dan heterokedastis. Juga tidak terjadi gejala multikoliniertias diantara variabel.

Tabel 2. Hasil Uji Regressi Linier Berganda, Uji F, Uji t dan Koefisien Determinasi

\begin{tabular}{|l|l|l|l|}
\hline \multicolumn{2}{|c|}{$\begin{array}{l}\text { Unstandardized } \\
\text { Coefficients (B) }\end{array}$} & t hitung & \\
\hline Constant & $-28,847$ & 3,928 & 0,01 \\
\hline IO & $-0,072$ & $-1,990$ & 0,058 \\
\hline LEV & 3,426 & 2,687 & 0,013 \\
\hline ROA & 15,130 & 2,137 & 0,043 \\
\hline FS & 1,001 & 4,018 & 0,001 \\
\hline DPR & 0,001 & 0,135 & 0,894 \\
\hline F hitung & & 5,674 & \\
\hline Sig & 0,001 & \\
\hline R & 0,736 & \\
\hline R square & 0,542 & \\
\hline Adjusted R Square & 0,446 & \\
\hline Sumber : Pengolahan Data & & \\
\hline & & & \\
\hline & & & \\
\hline & & & \\
\hline & & & \\
\hline & & & \\
\hline & & & \\
\hline & & & \\
\hline & & & \\
\hline
\end{tabular}

Sumber : Pengolahan Data (2014)

\section{ISSN 1858-3199 \\ JURNAL \\ MANAJEMEN BISNIS \\ STIE IBBI}

Dari tabel diatas diperoleh persamaan linier berganda sebagai berikut :

$\mathrm{Y}=-28,847-0,072 \mathrm{IO}+3,426 \mathrm{LEV}+15,130 \mathrm{ROA}+$ $1,001 \mathrm{FS}+0,001 \mathrm{DPR}+\mathrm{e}$

Hasil Uji F menyatakan bahwa secara serempak variabel IO, LEV, ROA, FS dan DPR signifikan mempengaruhi nilai perusahaan. Sementara itu secara parsial variabel variabel IO dan DPR tidak signifikan mempengaruhi nilai perusahaan.

Pengaruh Insider Ownership Terhadap Nilai Perusahaan

Dari hasil uji statistik ditemukan bahwa insider ownership tidak signifikan terhadap nilai perusahaan. Peningkatan jumlah kepemilikan saham oleh manajer ( insider ) tidak berpengaruh tehadap naik turunnya nilai perusahaan.

Dalam kaitan ini dapat dijelaskan bahwa kepemilikan oleh manajer tidak menjadi penting dalam rangka peningkatan nilai perusahaan. Kepemilikan saham insider dianggap tidak menjadi alat pengendalian yang efektif. Manajer tetap konsisten dengan tindakannya sesuai dengan drivenya walaupun memiliki saham di perusahaan tersebut.

Berarti dalam kaitan ini manajer menganggap segala tindakannya adalah merupakan tindakan yang benar, justru dia tidak mempersoalkan apakah dia memiliki atau tidak memiliki saham diperusahaan yang dikelolanya.Temuan ini tidak konsisten dengan dengan penelitian yang dilakukan oleh Soliha dan Taswan, Lestari, Taufik dan Yusralaini (2013)

Pengaruh Leverage Terhadap Nilai Perusahaan

Dari hasil pengujian ditemukan bahwa leverage positif signifikan mempengaruhi nilai perusahaan. Semakin tinggi komposisi hutang dibanding total kekayaan justru akan meningkatkan nilai perusahaan. Hasil ini menunjukkan bahwa penambahan hutang akan meningkatkan kinerja keuangan perusahaan. Dalam logika bisnis menambah hutang tidak menjadi masalah jika dapat menciptakan laba bersih yang tinggi. Temuan ini tidak konsisten dengan Sofyaningsih dan Hardiningsih (2011). 


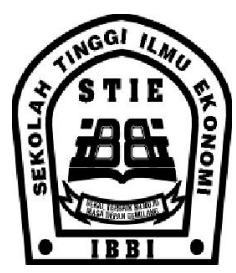

ISSN 1858-3199

JURNAL

MANAJEMEN BISNIS

STIE IBBI

Pengaruh Profitabilitas Terhadap Nilai Perusahaan

ROA signifikan mempengaruhi nilai perusahaan. Peningkatan kinerja perusahaan yang diukur dengan proxi ROA akan meningkatkan nilai perusahaan. Laba tinggi akan menyebabkan peningkatan laba ditahan yang pada akhirnya meningkat investasi sehingga mampu mendongkrak nilai saham.

Pengaruh Firm Size Terhadap Nilai Perusahaan

Hasil penelitian ini menunjukkan bahwa semakin besar aktiva perusahaan semakin meningkatkan nilai perusahaan. Artinya semakin kemampuan perusahaan untuk meningkatkan investasi dalam rangka penciptaan laba.

Laba yang tinggi akan mempengaruhi dividend yang akan diterima perusahaan yang dapat mendongrak nilai pasar saham yang akan mengakibatkan meningkatnya nilai perusahaan.

Pengaruh Dividend Payout Ratio Terhadap Nilai Perusahaan

Hasil penelitian ini menunjukkan dividend pay out ratio tidak signifikan mempengaruhi nilai perusahaan. Besarnya dividend yang diberikan pemegang saham tidak merespon nilai perusahaan.

Hal ini bisa saja disebabkan peningkatan dividend dianggap merupakan kebijakan yang tidak proporsional dalam meningkatkan investasi. Penelitian ini konsisten dngan Lestari, et.all (2013) dan Hardiningsih (2011).

\section{KESIMPULAN}

Penelitian ini menyimpulkan bahwa secara simultan terdapat pengaruh signifikan insider ownership, leverage, ukuran perusahaan, profitabilitas dan dividend pay out ratio terhadap nilai perusahaan yang diukurdengan price book value.

Namun secara partial kepemilikan saham oleh insider dan dividend tidak signifikan mempengaruhi nilai perusahaan.

\section{REFERENSI}

Ang, Robert. 2007.Buku Pintar : Pasar

Modal Indonesia.Mediasoft

Indonesia

Brigham, Eugene F; Joel F, Houston. 2010. Dasardasar Manajemen Keuangan. Jakarta : Salemba Empat.

Crutchley, CE dan M.R. Jensen. 2006. Changes In Coorporate Debt Policy : Information Asymetry and Agency Factors, Managerial Finance, 1996 : 22, 2 ; P. 1-14.

Darmadji, TjiptonodanFakhruddin, Hendri. 2012. Pasar Modal di Indonesia. Jakarta :PenerbitSalembaEmpat.

Ghozali, Imam. 2009. AplikasiAnalisis Multivariate dengan Program SPSS. Semarang: BadanPenerbitUniversitasDiponegoro

Harahap,

Sofyan.

2013. AnalisisKritisatasLaporanKeuangan.EdisiPe rtama. Raja GrafindoPersada. Jakarta.

Haruman, Tendi. 2008. Pengaruh Struktur Kepemilikan Terhadap Keputusan Keuangan Dana Nilai Perusahaan. Simposium Nasional Akuntansi XI. Pontianak

Horne, Van dan John, Wachowicz. 2012. Prinsip prinsipManajemenKeuangan. Jakarta :SalembaEmpat

Ikbal, Muhammad; Sutrisno, Ali Djamhuri.2011. PengaruhProfitabilitasdanKepemilikan

Insider TerhadapNilai Perusahaan DenganKebijakanUtang Dan KebijakanDividenSebagaiVariabel Intervening (Studipada Perusahaan Manufaktur di Bursa Efek Indonesia).Jurnal SNA 14 


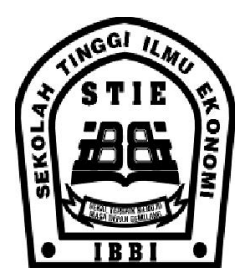

Kusumawati, D.N. 2005. Profitability and Corporate Governance Disclosure: An Indonesian Study. Indonesian Journal of Accounting Research, 10(2), 131-146. La Porta, R., Lopez-De-Silanes, F., and Shleifer, A. (1999). Corporate Ownership Around the World. The Journal of Finance, $\operatorname{LIV}(2)$, 471-516. Literature, 25(1), 121-132

Kusumawati, Rita dan Ade Sudento, 2005.AnalisisPengaruhProfitabilitas (Roe), Ukuran Perusahaan (Size) Dan Leverage Keuangan (Solvabilitas) Terhadap Tingkat Underpricing PadaPenawaranPerdana (Initial Public Offering/Ipo) Di Bursa Efek Jakarta.Utilitas.Vol $13 \quad$ No 1.JurnalmanajemenBisnis. Yogyakarta: FakultasEkonomiUniversitasMuhammadiya h

Lestari, Taufik dan Yusralaini (2013). Pengaruh Kebijakan Dividen, Kebijakan Hutang, Keputusan Investasi dan Kepemilikan Insider Terhadap Nilai Perusahaan (Studi Empiris pada Seluruh Perusahaan yang Terdaftar di Bursa Efek Indonesia 20082011). Jurnal

Rinawati dan Wardoyo. 2011. Analisis Pengaruh Insider Ownership, Size Terhadap Nilai Perusahaan (Studi Empiris pada Seluruh Perusahaan Automotive yang Terdaftar di Bursa Efek Indonesia 2006-2010). Jurnal

Rustendi, $\quad$ TedidanJimmi, $\quad$ Farid.2008. PengaruhHutangdanKepemilikanManajerial TerhadapNilai Perusahaan Pada Perusahaan Manufaktur.JurnalAkuntansi FE Unsil, Vol. 3, No. 1, hal. 412-423

Sujoko;Soebiantoro, Ugy. 2007. PengaruhStrukturKepemilikan, Leverage, Faktor Intern, danFaktorEksternTerhadapNilai Perusahaan (StudiEmpirikpada Perusahaan Manufakturdan Non Manufaktur di Bursa
ISSN 1858-3199

JURNAL

MANAJEMEN BISNIS

STIE IBBI

Efek Jakarta). Jurnal Manajemen dan Kewirausahaan, Vol.9 No.1, Maret 2007

Sugiyono. 2012. MetodePenelitianKuantitatif Kualitatif dan R\&D. Bandung :PT Alfabeta.

Sofyaningsih, Sri danHardiningsih, Pancawati. 2011. StrukturKepemilikan, KebijakanDividen, KebijakanUtangdanNilai Perusahaan. Semarang : Jurnal UniversitasStikubank

Wahidahwati, 2002.PengaruhKepemilikanManajerialdanK epemilikanInstitusionalpadaKebijakanHutan gPerusahaan :SebuahPerspektif Theory Agency. JurnalRisetAkuntansi Indonesia, Vol. 5, No. 1, hal 1-6

Weston, J Fred dan Copeland,Thomas. 2007. Manajemen Keuangan, Edisi Kesembilan.Jilid Dua. Jakarta: Binarupa Aksara. 